\title{
Detecting the impact of climate and disturbances on tree-rings of Fagus sylvatica L. and Quercus robur L. in a lowland forest in Cantabria, Northern Spain
}

\author{
Vicente Rozas* \\ Departamento de Biología de Organismos y Sistemas, Universidad de Oviedo, \\ Catedrático Rodrigo Uría, 33071 Oviedo, Spain
}

(Received 18 April 2000; accepted 9 October 2000)

\begin{abstract}
The influence of climate and disturbances on tree-ring widths of European beech and pedunculate oak were evaluated in a lowland forest of Northern Spain. From 1925 to 1980, 36\% of the variance of beech ring-width and 29\% of the oak one was explained by climate. The climatic models showed that low precipitation in July of the previous year limited the radial growth of beech, while oak one was instead restricted by water deficits in July of the current year. Ten main disturbance periods were identified from 1780 to 1997, among which the 1922-1935 one was the most important. Since beech trees showed suppressed growth from 1800 to 1920 , probably the forest canopy became denser during this time. The disturbance periods identified in 1922-1935 and 1948-1953 contributed to both increase the growth of beech above the expected, and intensify its climatic response. On the other hand, deviations of oak growth from the expected without-disturbance indices agreed with the disturbance history up to 1850 . From 1850 to 1997, oak growth became independent from disturbances sequence, yielding a constant climatic response in 1925-1980. The opposite effects of disturbances on both the radial growth and the climatic response of European beech and pedunculate oak are related to their different tolerance to shade. These results have relevant methodological implications on the analysis of climate-growth relationships, and on the reconstruction of past disturbance regimes by means of dendroecological techniques.
\end{abstract}

dendroecology / ring width / response function / forest disturbance / Kalman filter

Résumé - Effet du climat et des perturbations locales sur la croissance radiale de Fagus sylvatica L. et Quercus robur L. dans une forêt naturelle de Cantabria, Nord de l'Espagne. L'influence relative du climat et des perturbations locales sur la croissance radiale du hêtre et du chêne pédonculé a été analysée dans une vieille forêt naturelle du Nord de l'Espagne. Entre 1925 et 1980, $36 \%$ de la variance des largeurs de cernes du hêtre et $29 \%$ de celle du chêne s'expliquent par le climat. Les modèles climatiques élaborés montrent que la croissance radiale du hêtre est limitée par les précipitations du mois de juillet de l'année précédente, alors que celle du chêne l'est par le déficit hydrique du mois de juillet de l'année en cours. Dix périodes de perturbation de la croissance, d'origine non climatique, ont été identifiées entre 1780 et 1997, parmi lesquelles celle de 1922-1935 a été la plus importante. La croissance radiale des hêtres apparaît faible de 1800 à 1920 en raison de la fermeture du couvert forestier au cours de cette période. Puis des perturbations survenues en 1922-1935 et 1948-1953 entraînent une augmentation de la croissance, qui devient alors supérieure au signal commun. Conjointement, la réponse aux contraintes climatiques se renforce au cours des mêmes périodes. Chez le chêne, les déviations de la croissance par rapport au signal commun sont en accord avec l'historique des perturbations locales jusqu'en 1850. Puis la croissance devient indépendante de ces perturbations et converge avec le signal commun. Sa réponse au climat demeure constante de 1925 à 1980.

dendroécologie / largeur de cerne / fonction de réponse / perturbation / filtre de Kalman

* Correspondence and reprints

Tel. (34) 9851048 27; Fax. (34) 9851048 65; e-mail: vrozas@ sci.cpd.uniovi.es 


\section{INTRODUCTION}

In closed-canopy forests of temperate latitudes radial growth patterns of trees are determined by a complex interaction of several factors. The variation of ring width series is a linear combination of: (1) the trend related to the increase of the individual size and age, (2) the environmental signal related to climatic variability, (3) the standwide exogenous disturbance pulses, (4) the disturbance pulses with a local origin, and (5) the unexplained year-to-year variability not related to the former factors $[9,31]$. Thus, a ring-width series may be broadly decomposed into an age trend component, two common signal components (climate and exogenous disturbances), and two unique signal components (endogenous disturbances and unexplained variability) [9]. The common signal components allow to compare the patterns of wide and narrow rings among trees to establish the exact year in which the rings were formed $[14,40]$. By contrast, the unique signal components are characteristic of each tree, and in dense temperate forests they are strongly related to competition and local disturbances $[9,31]$.

Climatic signal is assumed to be broad scale in that all the trees in a stand will be affected similarly by the same set of climatic variables. Thus, the synchrony in the ringwidth pattern among trees in a site is mainly a consequence of variation in climatic parameters from one year to another $[14,15]$. The exogenous disturbance pulses affect the greatest part of individuals in a population, therefore being also components of the common signal [9]. Certain factors such as geomorphologic events, defoliating insect infestations, or pollutant depositions, are reflected in the ring-width series as exogenous disturbance signals. Exogenous disturbances can be identified through the comparison of the affected chronology with a control chronology obtained from another coexisting species with a similar climatic response (nonhost species, unaffected by defoliating insects $[15,41]$ ), or from other geographic areas not affected by the disturbance $[24,44]$. The exogenous disturbance signal can be also differentiated from the climatic signal by comparing the current chronology with the predicted indices estimated from climatic data $[11,25,30]$.

Disturbance pulses of local origin affect only a certain number of trees within a population, and they are originated by the sudden decrease of the competition intensity with the surrounding trees [27]. The disappearance of one or more trees due to a local disturbance releases space and resources, which is reflected in a sharp increase in the growth rate of adjacent surviving trees. In the last years they have been developed some filters to detect abrupt releases in radial growth, which permitted to derive past forest disturbance regimes [27, 31, 33]. By means of these techniques it has become possible to reconstruct the disturbance history of different types of temperate forests, and to know its influence on tree regeneration and forest dynamics [e.g. 23, 28, 44].

Many forests in Europe are constituted by European beech (Fagus sylvatica L.) and pedunculate oak (Quercus robur L.). The relationships between the climatic variation and the radial growth of both tree species in many European localities have been widely studied during the last decades $[4,5,13,17,18,20,22,34,38$, 42]. Dendroecological techniques have demonstrated to be efficient tools for reconstructing the past disturbance regime in many types of Fagus and Quercus forests [1, $2,3,16,33,37]$. Dendroecological reconstruction of the disturbance history have been achieved in some European forests $[8,33]$. However, the effects of local disturbances on the radial growth patterns of European beech and pedunculate oak have not been studied yet. The effects of disturbances on ring-width response to limiting climatic factors have not been investigated in any tree species either.

In this work, the individual and combined effects of climate and disturbances on the radial growth of these species were analyzed in a forest of the Cantabrian lowlands, Northern Spain. The objectives of this study were: (1) to know the climatic response of beech and oak in this locality, (2) to reconstruct the disturbance history of the forest under study, (3) to estimate the influence of past disturbance regime on radial growth patterns, and (4) to evaluate the synergistic effects of climate and disturbances on the radial growth of both species. The radial growth-climate relationships were explored by means of the correlation and bootstrapped response functions $[25,26,39]$. The correspondence between documentary sources about forest disturbances and the dendroecological reconstruction of stand history were also evaluated. The radial growth-disturbance relationships were estimated by comparing the reconstructed disturbance history with the deviations of the affected chronologies from the common signal. Finally, the possible interactions between the effects of climate and disturbances were examined by analyzing the temporal variation of climatic response through the Kalman filter technique.

\section{MATERIALS AND METHODS}

\subsection{Study site}

The forest under study is located in the western lowlands of Cantabria, Northern Spain, included in the Oyambre Natural Park. It is $6 \mathrm{~km}$ far from the shore line between the localities of Comillas and Cabezón de la Sal, close to the village of Caviedes $\left(43^{\circ} 20^{\prime} \mathrm{N}, 04^{\circ} 18^{\prime} \mathrm{W}\right)$. 
The soils are deep sandy brown earths, with parent material of sandstone and clay formed in the lower Cretacean. The Caviedes forest has an area of 110 ha, and is located on a gentle slope (8 to 50\%) north-east oriented, with altitudes ranging from 40 to $240 \mathrm{~m}$ asl. European beech and pedunculate oak are the dominant tree species in the forest canopy. Age structures of both oak and beech in the Caviedes forest reveal two clearly differentiated cohorts: the mature trees are 150-260 years old, and the young ones have 20 to 80 years in age [36]. The cores used in this study were taken only from mature, older than 150 years trees.

The Caviedes forest belongs to the Corona forest assemblage (2000 ha), which is now mainly composed by plantations of eucalyptus (Eucalyptus globulus Labill.), Monterey pine (Pinus radiata D. Don.), and red oak (Quercus rubra L.). During several centuries up to late 1800 s, the Corona forest was administered by the Spanish Royal Navy due to the excellence of their oak wood for naval building [12]. A first forest management plan was approved in 1901, which resulted in a drastic reduction to the half of the original forest surface during two decades. A second management plan authorized in 1942 conformed the forest as it can be currently observed, with the greatest part of the area occupied by plantations of eucalyptus and pine (more than $1000 \mathrm{ha}$ ). The Caviedes forest is the largest among three remnants of the native oak and beech-oak forest, which actually occupied a total surface of over 250 ha along the Corona forest assemblage.

\subsection{Climatic data}

A complete record of temperature and precipitation from 1924 to 1996 was obtained at the Centro Meteorológico Territorial de Asturias y Cantabria (Santander, Spain), $65 \mathrm{~m}$ asl, and $43.5 \mathrm{~km}$ east of the study site. The climate in the area under study is Atlantic, with temperate and wet winters, and periods of summer drought in occasional years only. Rainfall records at the weather station of Santander show a summer minimum (from June to August), and a maximum in autumn-winter (from October to December), with a mean annual precipitation of $1210 \mathrm{~mm}$ (figure 1). Maximum temperature values occur during the summer (from July to September), while minimum temperatures are observed in winter (from December to February), with a mean annual temperature of $14{ }^{\circ} \mathrm{C}$ (figure 1). Total annual rainfall and mean annual temperature series from 1924 to 1996 are shown in figure 1.

\subsection{Sampling, measurements, and chronologies computation}

The mature live trees ( 84 beeches and 31 oaks) within a 1.35 ha forest area were cored with a Swedish increment borer $40 \mathrm{~cm}$ in length, and $5 \mathrm{~mm}$ in the inside diameter of the bit. Furthermore, it was taken an additional random core sample of 20 beeches and 17 oaks from other locations in the Caviedes forest. Repetitive coring was achieved in order to ease the interception of

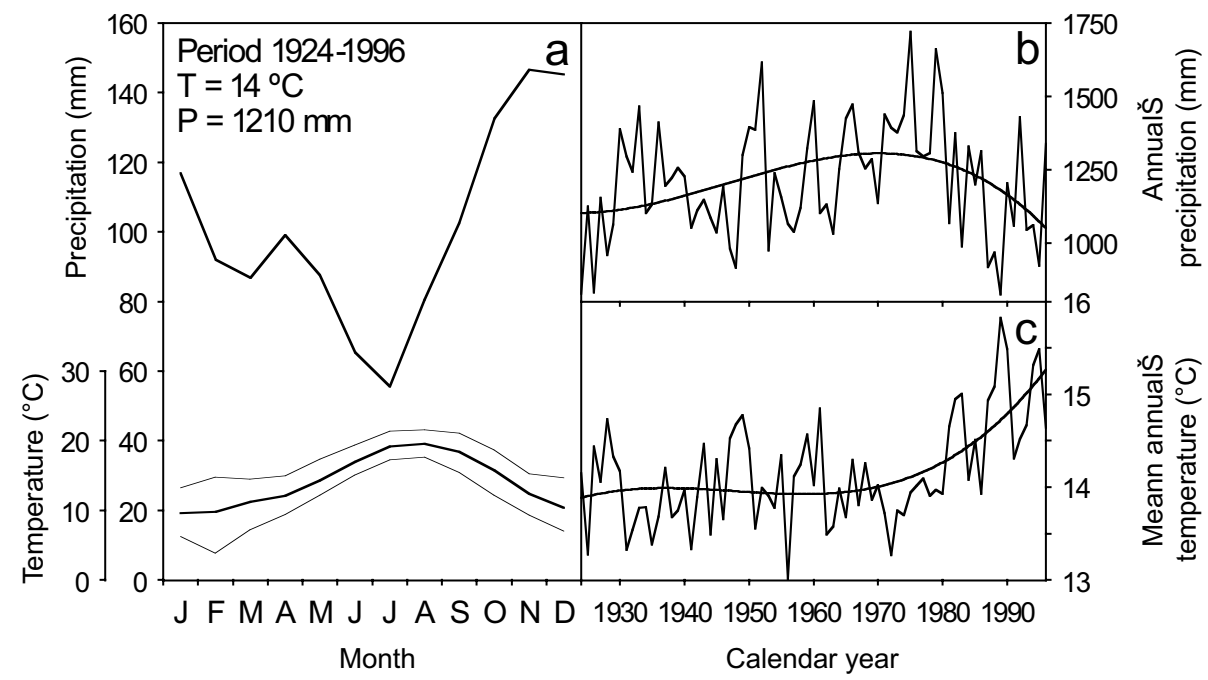

Figure 1. Climatic diagram of Santander, Spain $\left(43^{\circ} 27^{\prime} \mathrm{N}\right.$, $03^{\circ} 49^{\prime} \mathrm{W}, 65 \mathrm{~m}$ asl.) for the period 1924-1996 (a). The range of variation for mean temperature (thin lines) is shown. $\mathrm{T}$ and $\mathrm{P}$ : mean annual temperature and precipitation, respectively. Total annual precipitation (b) and mean annual temperature series (c) with their general trend. 
the pith, and to avoid faults or rottenness. Usually one core per tree was taken, but up to four cores were taken in a few trees to obtain at least a core appropriate for the objectives of the study. Cores were air dried, mounted, sanded, and the tree ring series were dated following the standard procedures [40]. The ring-width series of each sample were measured with the help of a stereomicroscope to the nearest $0.01 \mathrm{~mm}$ with a Velmex incremental measuring device (measurement platform, linear decoder, and digital readout unit) linked to a personal computer.

The program COFECHA was utilized in order to identify possible inconsistencies in the tree-ring dating and ring-width measurement procedures. This program accomplishes the cross-dating by calculating the correlation coefficients for different lags between each individual ring-width series and a dating master series [21]. The dating master series were calculated from those ringwidth series unequivocally correctly synchronized, without neither missing rings nor abrupt changes in growth patterns, and highly inter-correlated. Correlation coefficients were calculated by temporarily removing the series under examination from the master series to avoid comparing it against itself [21]. COFECHA permitted furthermore to date correctly several floating series that could not be visually synchronized due to anomalies in the outermost portion of the cores.

Two groups of different ring-width series for each tree species were selected on the basis of their cross-dating quality, in order to elaborate the corresponding chronologies. Group 1 included growth series that showed a good correspondence with the dating master series alone, i.e. those showing high global and by-segments correlation with the master series (correlation coefficients $\geq 0.50$ ). The series in this group came from both the study area, and the random sample from other locations in the Caviedes forest, thus group 1 cores were considered a control sample indicative of the common signal.

Group 2 was composed by a selection of cores coming exclusively from the study area, whose ring-width series showed a low correlation with the dating master series, both as a whole as well as in at least one segment. Low correlation with master series in one or more segments indicated that the tree had been affected by a disturbance differently from others at the site [21]. It was thus considered that the ring-width series belonging to group 2 reflected adequately the effects of local disturbances on radial growth.

Two different methods of ring-width series standardization and chronology computation were employed. In method 1 , the raw ring-widths were standardized by means of a two-step procedure: the series were first fit to a negative exponential or straight line and then to a cubic smoothing spline with a $50 \%$ frequency response of 50 years, which is flexible enough to reduce considerably non-climatic variance [10]. Autoregressive modeling of the residuals and biweight robust estimation of the mean were used to calculate the chronology indices in this method. Method 1 was only applied to radial growth series belonging to group 1 . Since the resulting chronologies from method 1 represent the climatic signal for the site, they were used to evaluate the radial growthclimate relationships.

In method 2, the radial growth series of both group 1 and group 2 were not detrended, fitting them instead to a horizontal line passing through the mean ring width of each series. The residuals of these fits were the quotients between the raw ring widths and the mean growth rate of each complete series, i.e. dimensionless indices comparable between single individual series. This standardization method preserves all the information contained in ring-width series, and emphasizes changes in treegrowth patterns as well as periods of deviation from average growth rates $[24,44]$. The final step of method 2 was the computation of the chronology as the arithmetic mean of the standardized indices, in order to give each series equal weight when combined into the chronology.

\subsection{Dendrochronological analysis}

Response functions were calculated taking the monthly mean temperature and total precipitation records as climatic predictors, and the index chronologies obtained through the method 1 as the dependent variables. Simple correlation coefficients between the ring-width indices and each of the climatic variables were calculated in order to derive correlation functions [6]. An interval of 15 months was chosen to define the climatic predictors, from June of the previous year to August of the current growth year. Since a change in the trend of annual rainfall and temperature series occurred toward 1980 (figure 1), the radial growth-climate relationships were studied for the period 1925-1980, which exhibited relatively homogeneous weather conditions. In response function analysis, the variation of ring-width indices was estimated through multiple regression, after extracting the principal components of the climatic predictors to avoid the intercorrelations between them [14]. The bootstrap method was employed to estimate $95 \%$ confidence intervals of the regression coefficients in response functions [19, 25, 26, 39]. Simple correlations and bootstrap method are more powerful tests than the traditional response functions $[5,6]$, so providing an accurate estimate of the climatic response. 
In this work, the time-dependent climatic response was analyzed through the Kalman filter technique [43, $45,46,47]$ to ascertain possible interactions between the effects of local disturbances and climatic factors on ringwidth variation. This method was adapted to estimate regression models with time-varying coefficients, which allowed to analyze the climatic response of radial growth in the time domain $[45,46]$. The Kalman filter was calculated for those climatic variables that were revealed as significant by the correlation and response functions. The index chronologies obtained through the standardization method 1 were again considered as the dependent variables.

The percentage growth change filter (PGC) [31] was used to detect possible tree-ring growth pulses caused by local disturbances, which can be identified as abrupt growth releases in the ring-width series. A growth release was here defined as a $100 \%$ increase in mean ring-width when consecutive groups of 10 years were compared. The $100 \%$ threshold in PGC is a conservative criterion to discriminate the local disturbance signals from sharp growth increases related to other factors [1, 2, $3,16,23,28,37]$. Furthermore, the years whose radial growth was lower than $0.5 \mathrm{~mm}$ were considered as growth suppressions [16]. Since the overall mean growth rate for both tree species was at least $1 \mathrm{~mm}$ per year $(1.5$ $\pm 0.4 \mathrm{~mm}$ for oak, and $1.0 \pm 0.4 \mathrm{~mm}$ for beech [36]), only rings whose width was minor than half of mean growth rate were considered suppressions. According to this view, during periods with high frequency of growth suppressions, competition between neighboring trees would have been intense (closed canopy phases), while the reductions of suppression frequency would be a consequence of the occurrence of local disturbances (canopy gaps appearance). The disturbance regime was thereafter reconstructed by means of the frequency distributions of growth suppressions and releases, as well as by averaging the individual PGC series of both studied tree species [27, 31, 33].

To evaluate the effects of disturbances on radial growth, tree-growth patterns of the ring-width series affected by disturbances (group 2) were compared with those not at such extent affected (group 1). In order to avoid rising differences due to distinct standardization methods, both affected and control chronologies were calculated through the method 2 . When two chronologies from different species or provenance are compared, they should be rescaled to approximately the same variance $[15,41]$. Since both affected and control chronologies show a very similar distribution, and derive from trees belonging to the same species and site, they were not corrected. Affected chronology indices were subtracted from the corresponding indices of the unaffected or con- trol chronology. The resulting deviation chronology reflected the effects of local disturbances on radial growth patterns, which were compared against the reconstructed disturbance history. Differences between growth indices of the affected and control chronologies were tested with the paired $t$-test, for periods defined on the basis of the disturbance history and changes in radial growth patterns.

The relationships between the reconstructed disturbance history and the variation of radial growth patterns must be interpreted with caution because of certain limitations of these data $[24,27,31,41,44]$. The most relevant restrictions are: (1) The loss of radial growth sequences by death of individuals, partial cores extraction, or an inappropriate sampling design, which can reduce or eliminate the signal of some disturbance events. (2) The distinction between radial growth pulses caused by disturbances and those related to variations in other environmental factors is very difficult. (3) The delay that might be expected in the response of tree growth to disturbances, so that the correspondence between disturbance occurrence and growth pattern variation could not be exactly established. (4) The unaffected chronologies are not perfect "controls" for the climatic signal because all tree-ring series reflect varying degrees of both climatic and non-climatic factors. Therefore, deviations from the control chronology will contain certain variations not related to disturbances. First and second restrictions were minimized by systematic and repetitive coring of all the live trees included in the area under study, and through the utilization of the strictest criterion for disturbance signal identification, respectively. Third and fourth restrictions do not have a methodological solution, therefore they should be assumed in the results as non-quantifiable bias sources.

\section{RESULTS AND DISCUSSION}

\subsection{Effects of climate on radial growth}

The index chronologies used to analyze the climatic response of beech and oak are plotted in figure 2, and their characteristics are presented in table I. Response functions showed that $35.8 \%$ of the variance in beech ring-width indices and $29 \%$ of the oak one can be explained by climate alone (figure 3 ). The percentages of radial growth variation related to climate in the Caviedes forest, are within the usual range in other western Europe localities, varying between 5.8 and $65 \%$ for beech $[5,13$, 20], and between 5 and $72 \%$ for oaks [13, 17, 22, 34]. Three possible explanations for the weak response of growth to climate are suggested: (1) The environmental conditions in the forest under study are not restrictive for 
Table I. Characteristics of the tree-ring chronologies of European beech and pedunculate oak at the Caviedes forest, Cantabria, calculated by means of the method 1 (see text).

\begin{tabular}{lcc}
\hline & Beech & Oak \\
\hline Number of trees / cores & $23 / 25$ & $17 / 20$ \\
Number of rings & 5015 & 3278 \\
Chronology span & $1773-1997$ & $1772-1997$ \\
Standard deviation & 0.233 & 0.200 \\
Mean sensitivity & 0.204 & 0.173 \\
First order autocorrelation & 0.424 & 0.332 \\
Optimum common interval span & $1834-1996$ & $1827-1973$ \\
Number of trees / cores in common & & \\
interval & $22 / 24$ & $11 / 14$ \\
Mean correlation between trees & 0.338 & 0.289 \\
Signal to noise ratio & 13.96 & 4.47 \\
Variance in first eigenvector $(\%)$ & 42.33 & 36.46 \\
\hline
\end{tabular}

tree growth (temperate and wet climate, deep soils, sea proximity, low altitude). (2) Resource competition from surrounding vegetation probably obscured the climatic signal on radial growth [31]. (3) The particular microclimate of the study area could significantly differ from the climatic records of the weather station. The later is not quite probable, but all three explanations are possible, and of course all of them combined can account for this weak climatic response.

Correlation function showed a significant reverse response of beech growth to temperature in the previous July and in the current June-July, as well as a significant positive response to precipitation in the previous July (figure 3). Both bootstrapped response function and mul- tiple least-squares regression showed a significant positive response of beech ring-width indices (RWI) to precipitation only in the previous July (PPJ) (figure 3; RWI $=0.8849+0.0020$ PPJ, $\left.R^{2}=0.125, P=0.0075\right)$. The climatic response of beech in the Caviedes forest roughly coincided with the radial growth-climate relationships for this species in some other European localities.

The inverse effect of temperature in previous July is coincident with the results obtained in the Atlantic coast of Northern Germany [13], and in the Montseny mountains (north-eastern Spain), the later subject to Mediterranean climate [20]. Inverse response to temperature in the current June-July also coincided with climatic response of beech in the Italian pre-Alps and again in the Montseny mountains $[20,35]$. The positive effect of precipitation in the previous July has been also stated in Montseny. However, the inverse effect of temperature from the current February to April, and the positive response to precipitation in the current June and July, observed in different beech populations in the Mediterranean or sub-Mediterranean mountains (Apennines [5], Montseny [20], and Italian pre-Alps [35]) has not been evidenced in the Caviedes forest (figure 3). Presumably, the Atlantic climate in the area under study is not comparable with the one in the Mediterranean mountains, which is limiting for beech growth to a greater extent than at the Caviedes forest.

Correlation function of oak showed a significant climatic response of radial growth in the current July only, negative to temperature and positive to precipitation (figure 3). Bootstrapped response function as well as ordinary least-squares regression showed a significant

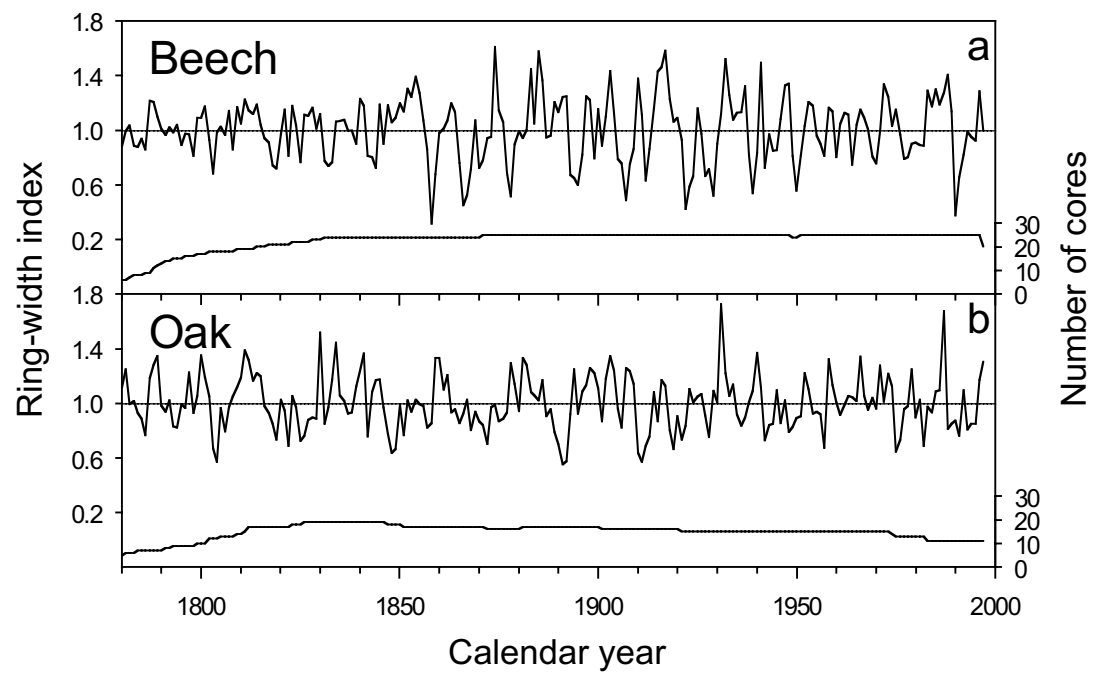

Figure 2. Tree-ring chronologies of European beech (a) and pedunculate oak (b) at the Caviedes forest, Cantabria, calculated by means of the method 1 (see text). The cores sample size is also plotted. 


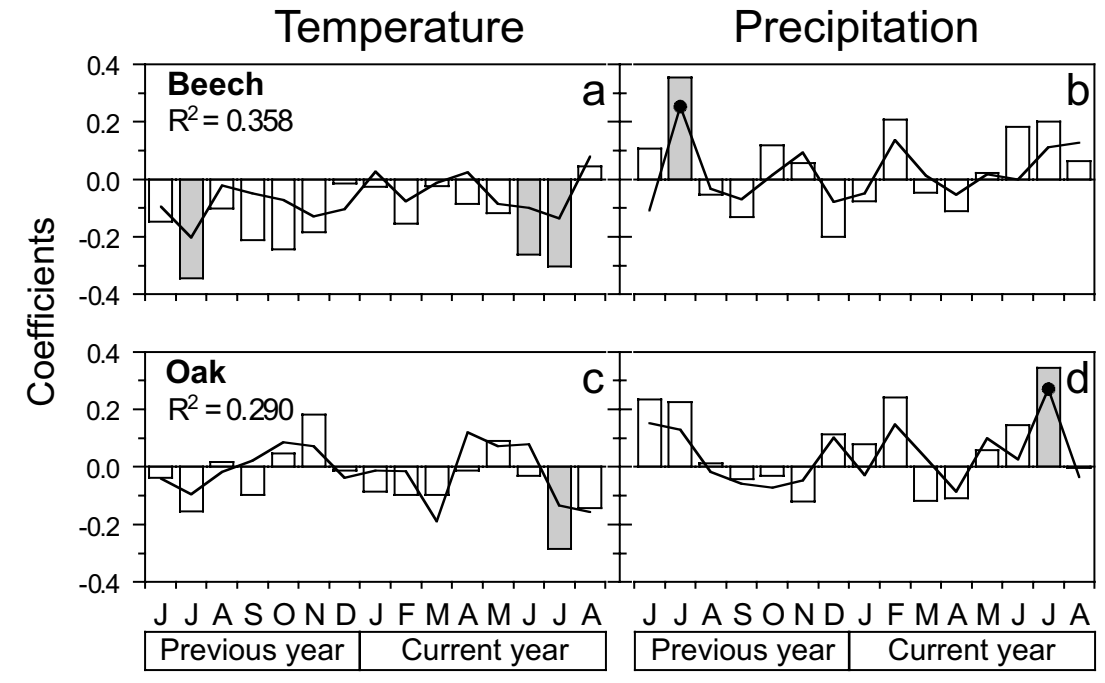

Figure 3. Correlation (bars) and response functions (lines) of European beech $(\mathrm{a}, \mathrm{b})$ and pedunculate oak (c, d) for monthly mean temperature and total precipitation, in the period 1925 1980. Shaded bars and solid points indicate months of significant coefficients at the 0.05 level. $R^{2}$ is the variance explained by climate, according to the response functions. positive response of oak ring-width indices to precipitation in the current July (PCJ) alone (figure 3; RWI = $0.9214+0.0016$ PCJ, $\left.R^{2}=0.118, P=0.0094\right)$. The negative relationship with temperature in July has been verified also in other southern European locations, as in Tuscany, Italy [38], where summers are very hot. In general, the radial growth of deciduous oaks in the Mediterranean region is negatively related to the temperature during May, June and July of the current growth year [42]. However, climatic response of oak growth to summer temperature in northernmost locations in western Europe is the opposite. In the British Isles, oak growth often shows a positive response to temperature during July [34], likely because water deficit in summer is not as pronounced as in Cantabria. The positive response to precipitation in the current July is also frequent in other European locations. In various Atlantic, Mediterranean and central European areas, oak radial growth showed a positive relationship with precipitation in May to July [4, 17, 34, 38]. Furthermore, the growth of deciduous oaks in the Mediterranean region was favored by precipitation during May to August [42]. Thus, the positive effect of summer rainfall on oak ringwidths is a general feature throughout Europe.

The results reveal the importance of summer precipitation and temperature on the radial growth of European beech and pedunculate oak. July is the driest month and one of the warmest in the study area (figure 1). Thus, the probability that limiting conditions for tree growth due to drought arise is greater in July than in other months. The radial growth of beech showed to be more sensitive to summer drought in the previous year than during the growth season, suggesting a significant preconditioning by climate during the previous year. This would explain the notable decrease of beech growth in 1990 noticed in $97 \%$ of the cores, as a consequence of the low precipitation and high temperature registered in 1989 (figure 1). On the other hand, summer precipitation and temperature in the current growth year alone did affect the radial growth of oak, which indicates that this species is not significantly conditioned by climate during the previous year.

A period of summer drought occurrence is more probable in the Cantabrian lowlands than in other locations at the Atlantic region, but less probable than in the Mediterranean region. Thus, the climate at the Cantabrian lowlands could be defined as Atlantic "without wet summers" in comparison with northernmost localities at Atlantic Europe, because of the pronounced decline of precipitation from June to August, and especially during July. This is a common trait with the Mediterranean climate, which showed a drought period reaching several months. The likely occurrence of drought during July limits the radial growth of the trees, as a consequence of the deficient water balance resulting of low precipitation and relatively high temperature. By contrast, during the other months the climatic conditions in the Cantabrian lowlands are not quite restrictive, and thus they do not limit the growth of trees. Being this true, climatic response of the radial growth of beech and pedunculate oak in the Caviedes forest was consistent with the climate and the environmental conditions in the study area, showing a poor climatic signal and a significant sensitivity to summer drought. 


\subsection{Disturbance history reconstruction}

The results indicate that the dendroecological reconstruction of past disturbance regime is reliable enough. On the basis of the frequency distribution of growth releases, ten mayor disturbance periods were identified in the study area along the last 220 years (figure 4 and table II). These periods were defined as at least four consecutive years showing growth releases, against the transitional periods which reached a mean frequency of releases of less than one per year. The releases that happened during the transitional periods were also scattered, and affected too few trees at once to be considered indicative of relevant disturbances. All the identified disturbance episodes were coincident with increasing peaks in the PGC average chronologies of beech and oak (figure 4), and seven of them coincided with significant reductions in the frequency of growth suppressions (table II). Very likely, the considered $100 \%$ in PGC threshold does not detect all disturbance pulses [27], as evidenced by some peaks in the mean PGC chronologies of beech and oak, which were not identified as disturbances from the releases distribution. A previous study does suggest that mature, overstory oaks tend to respond conservatively to canopy disturbances, so that the $25 \%$ minimum threshold in PGC seems more adequate to identify growth releases from mature oaks [31]. But yet considering that frequency distributions of growth releases infra-estimates the true disturbance regime, the main disturbances that occurred in the study area were correctly identified.

Along the 19th century, four release episodes were identified. During this time, the forest was been yet managed by the Spanish Royal Navy, periodically logging mature oaks carefully selected to provide specific ship pieces [12]. From 1828 to 1832 , only 9 growth releases

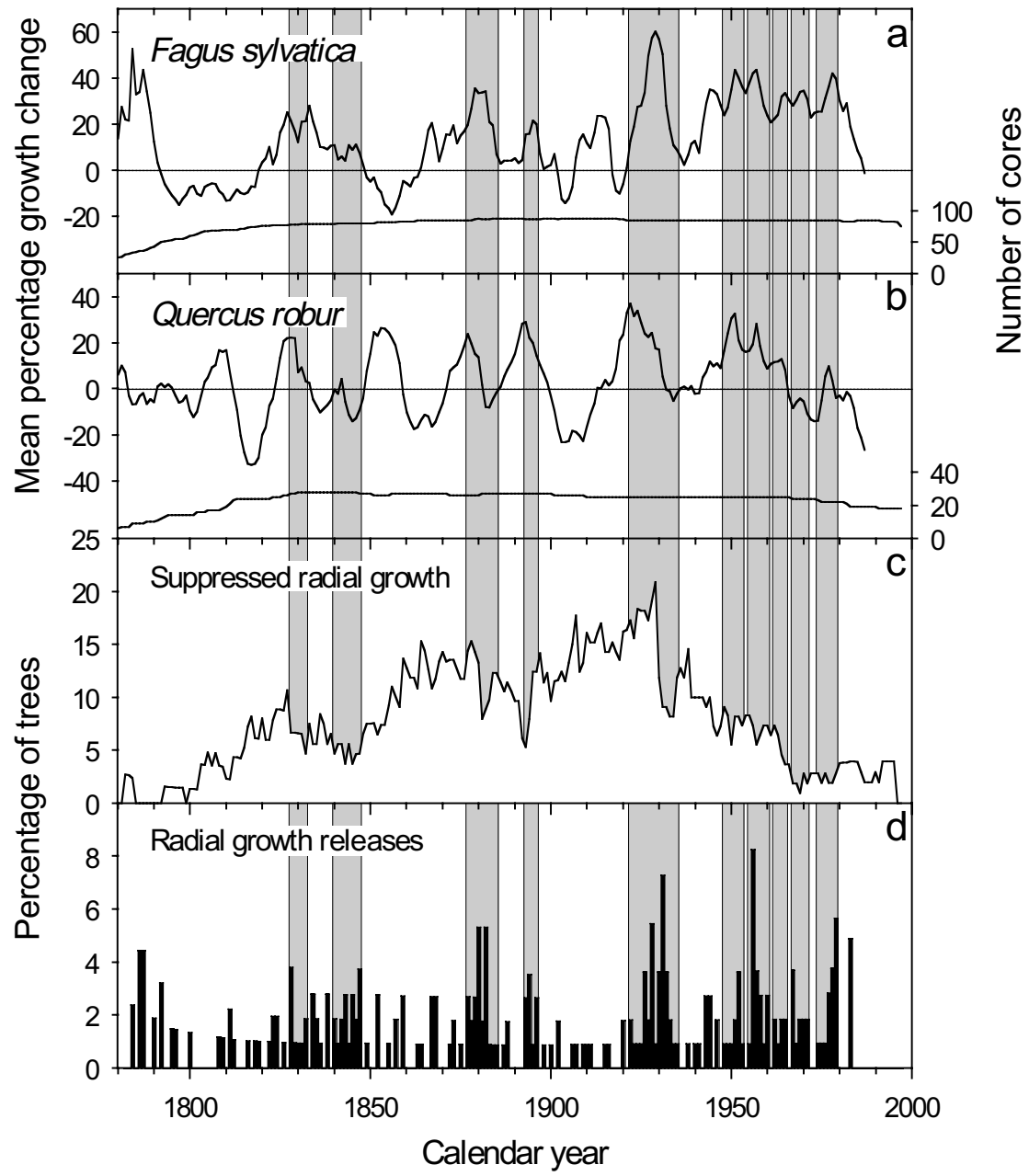

Figure 4. Mean percentage growth change chronologies of European beech (a) and pedunculate oak (b) with their respective number of cores. Percent of live trees with suppressed radial growth (c) and showing radial growth releases (d). The shaded intervals correspond to the identified disturbance periods. 
Table II. Main disturbance periods identified in the study area on the basis of the distribution of growth releases. The number and density of releases, the mean and maximum PGC values, and the change in percentage of suppressions of the different periods are showed. The change in mean percentage of suppressions was calculated as the 10-year mean percentage after the disturbance minus the preceding 10-year mean. The significance for differences between means according to unpaired $t$ tests is indicated.

\begin{tabular}{|c|c|c|c|c|c|}
\hline Period & $\begin{array}{l}\text { Number } \\
\text { of } \\
\text { releases }\end{array}$ & $\begin{array}{c}\text { Mean } \\
\text { number of } \\
\text { releases per year }\end{array}$ & $\begin{array}{c}\text { Mean PGC } \\
\text { of } \\
\text { releases }\end{array}$ & $\begin{array}{l}\text { Maximum } \\
\text { PGC } \\
\text { of releases }\end{array}$ & $\begin{array}{c}\text { Change in mean } \\
\text { percentage of } \\
\text { suppressions }\end{array}$ \\
\hline $1828-1832$ & 9 & 1.80 & 369 & 1172 & $-1.52 *$ \\
\hline $1840-1847$ & 18 & 2.25 & 137 & 201 & +0.46 n.s. \\
\hline $1877-1885$ & 25 & 2.78 & 197 & 495 & $-2.56 * * *$ \\
\hline $1893-1896$ & 11 & 2.75 & 207 & 577 & $+2.01 *$ \\
\hline $1922-1935$ & 38 & 2.71 & 191 & 562 & $-6.67 * * *$ \\
\hline $1948-1953$ & 10 & 1.67 & 194 & 343 & $-1.32 *$ \\
\hline 1955-1960 & 21 & 3.50 & 185 & 425 & $-1.80 * *$ \\
\hline $1962-1965$ & 7 & 1.75 & 147 & 227 & $-4.57 * * *$ \\
\hline 1967-1971 & 11 & 2.20 & 201 & 493 & $-3.93 * * *$ \\
\hline 1974-1979 & 16 & 2.67 & 186 & 342 & $+0.95 *$ \\
\hline
\end{tabular}

n.s.: non significant; $*: P<0.05$; **: $P<0.01$; ***: $P<0.001$.

were registered, although a significant reduction in the percentage of suppressed trees, and the maximum PGC value $(1172 \%)$ occurred during this period (table II). During the 1840-1847 period 18 growth releases were accounted, which were not very intense (up to $201 \%$ in PGC), and were not linked to a reduction in the frequency of suppressed trees. Probably along the later 1700s and the earlier 1800 s many radial growth releases corresponded to the canopy accession dates of the actual mature trees, but were not coincident with significant reductions in the canopy density, as suggested by the rising trend in the percentage of suppressed trees.

By contrast, during the $1877-1885$ period 25 trees showed a growth release (22\% of all the sampled trees), and a highly significant reduction in the frequency of suppressed trees was observed. This indicates a decrease in canopy density (table II). This disturbance was the most important one during the 19th century, and roughly coincided with the last harvesting operations by the Spanish Royal Navy during the 1870s [12]. In the 1893-1896 period 11 trees showed a growth release, while the number of suppressed trees significantly increased (table II). This result can seem paradoxical if its interpretation is made in a context of canopy disturbances due to windthrown or logging. But a forest report written in 1907 indicates that at the beginning of the 20th century a fungus disease heavily affected the oaks in this forest. The blight can be attributed to the oak powdery mildew (Microsphaera alphitoides Griff. \& Maubl., Erysiphaceae), which reduced the growth of oaks, and killed over 5000 oak trees along the 2000 ha area of the whole Corona forest. The beginning of fungus disease could have occurred at the 1893-1896 period, when the neighboring trees of the affected oaks experienced a growth release. The occurrence of a period of suppressed growth of oaks was manifested through the descending peak in the PGC chronology of oak that extends from 1900 to 1912 (figure $4 b$ ), and through the increment in the percentage of suppressed trees started in 1893 (figure 4c).

During the first two decades of the 20th century, intensive logging was carried on along the Corona forest assemblage. This implied the reduction of wood amount to $50 \%$ in only twenty years. But this did not affect the Caviedes forest, because logging was focused in other stands, which are nowadays plantations of eucalyptus, Monterey pine, and red oak. The period 1922-1935 showed the most severe disturbance recognized in the whole interval under study. During this period 38 individuals experienced a growth release, which represents $33 \%$ of all the sampled trees (table II). In addition, this event coincided with the greatest peak maximum recognizable in the PGC chronologies (figure 4), as well as with the largest reduction in the percentage of trees with suppressed growth (table II). This suggests a drastic reduction in forest density. This period seems to be in fact composed by two disturbance episodes: a first episode with maximum incidence on tree growth between 1926 and 1928, and a second episode which caused an increase in the frequency of growth releases between 1930 and 1933. These episodes could be due to either artificial or natural forest clearance. Unfortunately, no data about logging or storm occurrence in the 
Caviedes forest during the third and fourth decades of the century were found.

In February 1941 a hurricane affected the coastal plain in the Cantabrian lowlands. Tree rings indicated that this event was not a relevant incidence in the study area, probably because the wind blew from the south, while the Caviedes forest is north-northeast oriented. But a large stand nearby the study area was logged in 1951. From this time to the present, no logging of live trees was accounted in the Caviedes forest, and all the disturbances occurred as a consequence of natural forces. Probably, the frequency of the disturbances increased during the second half of this century because the dominant trees became physically unstable when size and age increase. For example, in winter 1954 a violent storm affected the forest, and many large trees uprooted or snapped throughout. Both 1951 and 1954 disturbance events were identified as periods of increment in the frequency of growth releases, and coincided with significant reductions in the percentage of suppressed trees (table II and figure 4).

Between 1961 and 1971, two minor disturbance periods were identified. Both periods were very likely due to local tree falls, and coincided with a significant reduction in the percentage of suppressed trees (table II). These results indicate that as a consequence of both disturbances tree density in the area under study decreased, at least at a local scale. Finally, in winter 1978 a cyclone devastated a Monterey pine plantation located $0.8 \mathrm{~km}$ apart from the Caviedes forest, and as a consequence of the same event some large trees felt down at the study area. In contrast with the other disturbances due to canopy opening occurrence, this event coincided with a significant increment in the percentage of suppressed trees (table II). This happened because the 1978 cyclone occurred when many young trees of the new cohort raised over 1920 reached the main forest canopy. The increase of canopy density due to the incorporation of new trees is reflected in the rising trend in the percentage of suppressed trees starting in 1969 (figure 4c).

\subsection{Effects of disturbances on radial growth}

The control and affected chronologies plotted in figure 5 were composed by a very similar number of samples, and were significantly correlated $(R=0.71$ for beech and $R=0.59$ for oak; $N=218$ and $P<0.001$ for both tree species). On the basis of both the sequence of disturbances and the changes in radial growth patterns, seven consecutive periods were considered (table III). The agreement between the deviations from expected ring-width indices and the disturbance history is consis- tent with the biological characteristics of each species. From 1780 to 1806 , the proportion of individuals with suppressed growth was always lower than $5 \%$, which indicates that an open forest canopy existed at that time (figure 4). The radial growth of beech and oak during this initial period was significantly greater than indicated by the control chronologies $(P=0.015$ for beech, $P<$ 0.001 for oak; table III). This would be expected in young trees grown without intense competition.

During the following 115 years, the percentage of trees with suppressed radial growth increased gradually from $5 \%$ to $20 \%$, i.e. the forest canopy became increasingly dense. During this period (from 1807 to 1921) the radial growth of beech was significantly lower than expected from the control chronology $(P<0.001$ in all tests; table III), and rising peaks were registered in the beech deviation chronology that coincided with the disturbance periods (figure 5). Presumably many of the samples used to elaborate the affected-by-disturbances chronology of beech were taken from trees that during this time occupied a non-dominant position in the forest canopy. In this case their radial growth would have been suppressed as a consequence of growing under dominant individuals. This is a normal behavior in beech, because it is a shade tolerant species, able to survive during long time periods under the forest canopy $[16,33]$.

The disturbances identified from 1922 to 1935 caused a pronounced reduction in the proportion of individuals with suppressed growth, from over $20 \%$ to less than $10 \%$ in absolute figures (figure 4), and $6.67 \%$ in average (table II). This meant a sudden decrease of tree density in the forest canopy. As a result, the radial growth of affected beeches from that moment to the present was significantly greater than indicated by the control chronology ( $P<0.001$ in all tests; table III and figure 5). In addition, the disturbances that happened during the periods 1948-1953 and 1974-1979 contributed to increase the positive deviation of beech growth from the climatic signal. These are expected consequences of the shade tolerance of beech, which allowed even the mature individuals to experience notable increases in the radial growth rate as a response to the release of available space [33].

Oak growth during the period 1807-1921 alternated between intervals of significantly lower and greater indices than the control chronology ( $P$ ranged from 0.031 to be $<0.001$; table III), and the deviation chronology of oak coincided with the sequence of disturbances up to 1850 (figure 5). However, from over 1850 to 1997 it was not evidenced a clear relationship between oak growth deviations and the disturbances sequence. From 1922 to 1973 the ring-width indices of the affected oak chronology were significantly greater than that of the 


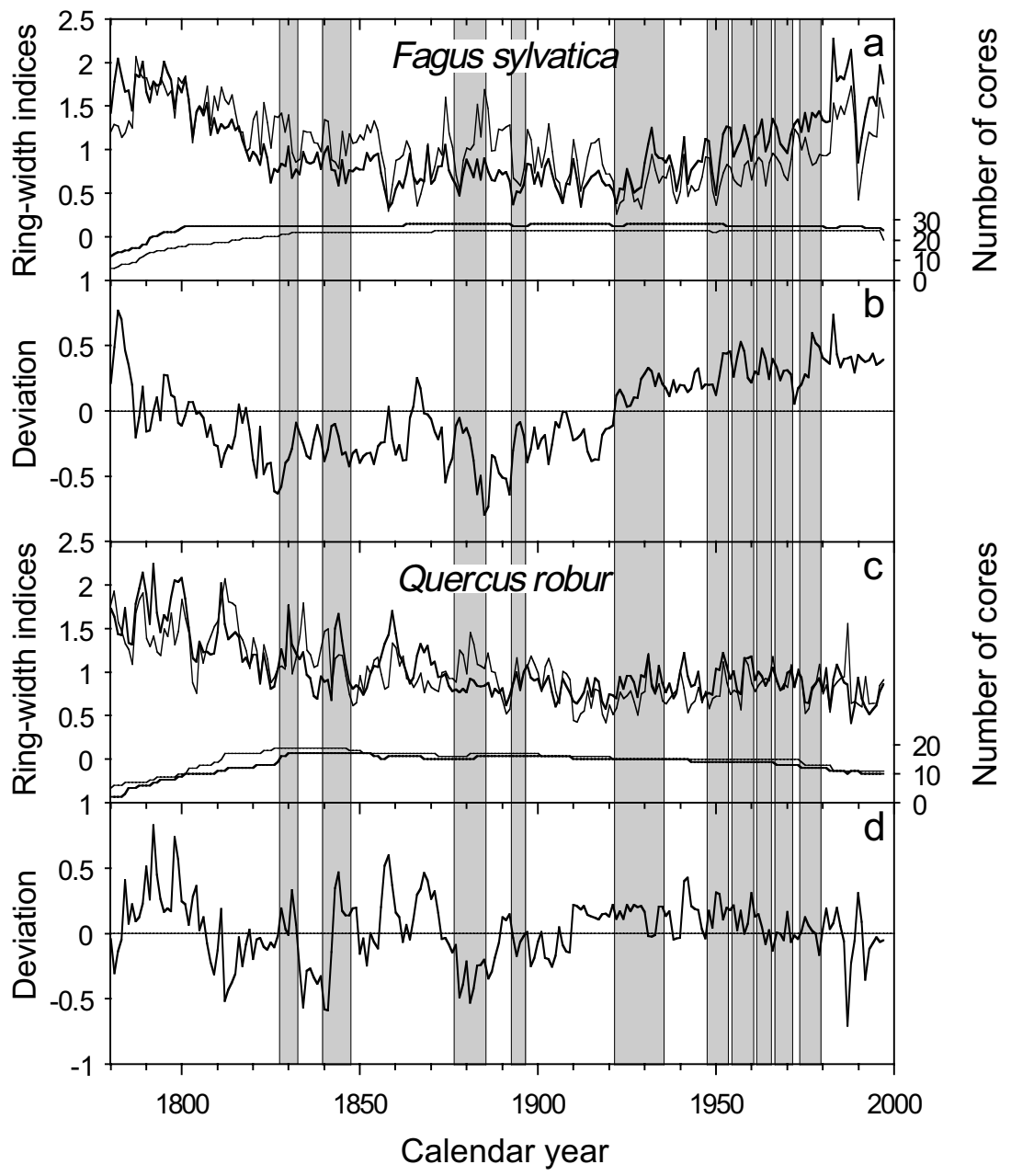

Figure 5. Affected (bold line) and control (thin line) tree-ring chronologies of European beech (a) and pedunculate oak (c) calculated by means of the method 2 (see text), with their respective number of cores. Deviation chronologies of beech (b) and oak (d) calculated as the difference between the affected and control chronologies. The shaded intervals correspond to the identified disturbance periods.

Table III. Periods recognized in the study area on the basis of both growth releases distribution and changes in the deviation chronologies of beech and pedunculate oak. $N$ : number of years. The results of paired $t$-tests for significance of deviations between mean affected and control indices in each period are showed.

\begin{tabular}{|c|c|c|c|c|c|c|c|}
\hline \multirow[b]{2}{*}{ Period } & \multicolumn{4}{|c|}{ Beech } & \multicolumn{3}{|c|}{ Oak } \\
\hline & $N$ & Mean deviation & Paired $t$ & $P$ & Mean deviation & Paired $t$ & $P$ \\
\hline $1780-1806$ & 27 & 0.127 & 2.61 & 0.015 & 0.225 & 4.68 & $<0.001$ \\
\hline $1807-1839$ & 33 & -0.285 & -9.60 & $<0.001$ & -0.153 & -4.30 & $<0.001$ \\
\hline 1840-1876 & 37 & -0.227 & -7.80 & $<0.001$ & 0.099 & 2.25 & 0.031 \\
\hline 1877-1921 & 45 & -0.278 & -9.84 & $<0.001$ & -0.074 & -2.43 & 0.019 \\
\hline $1922-1947$ & 26 & 0.188 & 11.68 & $<0.001$ & 0.135 & 5.35 & $<0.001$ \\
\hline $1948-1973$ & 26 & 0.309 & 13.33 & $<0.001$ & 0.085 & 3.46 & 0.002 \\
\hline 1974-1997 & 24 & 0.403 & 18.21 & $<0.001$ & -0.029 & -0.73 & 0.474 \\
\hline
\end{tabular}

control one $(P \leq 0.002)$, whereas from 1974 to 1997 no significant deviations between both oak chronologies were found $(P=0.474$; table III). From 1922 the growth of affected by disturbances oaks decreased gradually to become indistinguishable from the unaffected ones in the last decades.

The independence of oak growth from the changes in local conditions could be a consequence of that the 


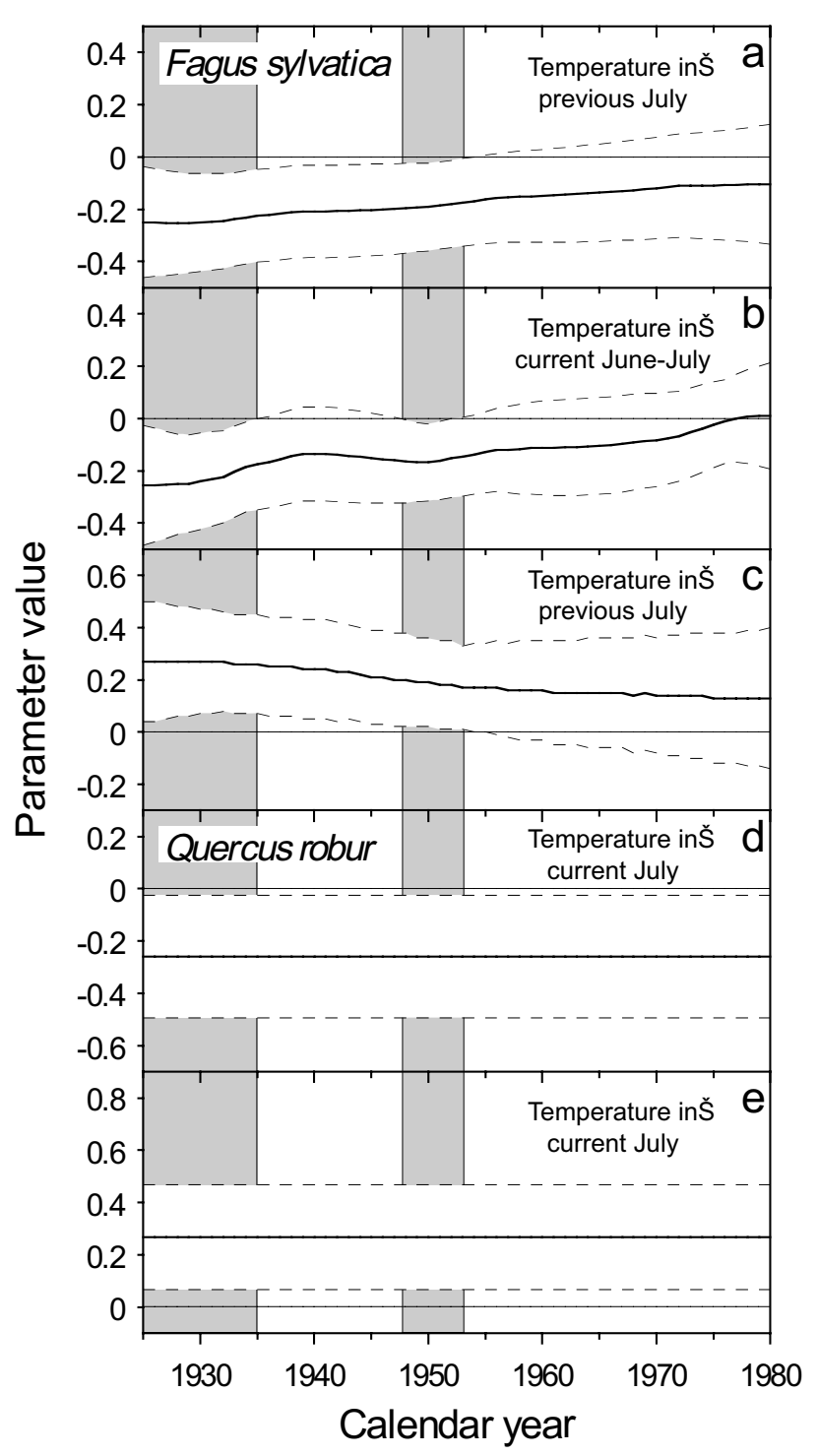

Figure 6. Time-dependent response functions of European beech $(a, b, c)$ and pedunculate oak (d, e) obtained by means of the Kalman filter technique for the period 1925-1980. The dashed lines represent the $95 \%$ confidence interval for the parameter values. The shaded intervals indicate the 1922-1935 and 1948-1953 disturbance periods.

mature oaks cored are dominant or sub-dominant trees in the forest canopy. While before reaching that status their radial growth responded to a large extent to local disturbances, after acceding at the superior canopy level, their growth became relatively independent of such kind of variations [27, 31]. In 1850, the cored oaks were between 50 and 110 years old, and most of them would have already reached the superior layer of the canopy. As distinct from beech, oak is a shade intolerant species, therefore the surviving mature trees are usually large dominant individuals in the upper forest canopy $[1,2]$. Probably the non dominant oaks which would have preserved the effects of the local disturbances in their radial growth series died throughout the forest history and therefore they were not sampled. The convergence between both affected and control oak chronologies, could be expected in dominant mature oak trees, whose growth became more and more independent of local conditions with time [31], becoming to fit to a large extent to the climatic signal.

\subsection{Synergistic effects of disturbances and climate on radial growth}

The climatic response of beech varied in time, while that of oak was constant during the period 1925-1980, as revealed by the Kalman filter method (figure 6). The temporal variability of the climatic response of European beech has been yet proved in a previous study [29]. The radial growth of beech was negatively influenced by temperature in the previous July during the period 1925-1953, but it did not show a significant influence of this variable in 1954-1980. Temperature in current JuneJuly also influenced negatively beech growth during the periods 1925-1935 and 1948-1952, with no significant relationships in other years. On the other hand, the positive influence of precipitation on beech growth in the previous July was significant for the period 1925-1954, whereas these were not related from 1955 to 1980 (figure 6). According to these results, the significant effect of summer temperature and precipitation on beech growth in the Caviedes forest, was synchronic ( \pm 1 year) with the disturbance periods identified during the years 1922-1935 and 1948-1953. Thus, these disturbance periods reinforced the effects of summer temperature and precipitation on beech's radial growth.

The interpretation of the combined effects of disturbances and climate on the radial growth of beech is contradictory. It would be expected than the non-dominant and stressed trees exhibit a greater sensibility to climatic factors than the dominant non-stressed individuals. For example, the influence of climate on the radial growth of Norway spruce increases when the dominance and the vitality of trees become reduced [7]. Also, in different species of trees growing in dense mesic forests, the understory individuals are significantly more sensitive to drought than dominant trees of the same species [32]. By contrast, when the climatic response of European beech was studied for different competition classes, trees under 
low competition levels showed a greater response to climatic variation than individuals under intermediate or high competition levels [35]. The occurrence of a disturbance implies a sharp decrease of competition intensity. Therefore, the agreement between disturbance periods and significant climatic response of mature beech trees in the Caviedes forest would be explained by the decrease of competition intensity during the disturbance. However, during the period 1954-1980 four disturbance events were identified, and the percentage of trees with suppressed radial growth was small (from $1 \%$ to $8 \%$; figure 4), all indicating a poor competition intensity. Thus, the lack of a significant climatic response from 1954 to 1980 probably indicated that climate was not limiting for beech during this time.

On the other hand, the effects of temperature and precipitation in the current July on oak radial growth were significant along the whole analyzed period, negative for temperature and positive for precipitation (figure 6). The influence of climate on oak growth was constant in the time and independent of disturbance occurrence. The stability of oak's climatic response across different periods of time has been yet evidenced in different western Europe locations [18]. This constitutes another evidence of that mature oaks exhibit radial growth patterns being independent to a great extent of the local disturbances. This hypothesis should be tested by analyzing the climatic response of young non-dominant oaks, which would have been influenced by the disturbance regime. This being true, the feasible independence of mature oaks growth from disturbances when many of them would have reached the upper canopy, could be more robustly stated.

An effective way of studying the interaction between the effects of disturbances and climate would be the time-dependent analysis of the radial growth-climate relationships in single individuals affected by particular disturbances [46, 47], or in chronologies calculated from trees affected by the same sequence of disturbances. The Kalman filter technique has proved to be an effective tool for the analysis of the synergistic effects of disturbances and climate on tree growth, whose interactions are very difficult to identify when the climatic response is not studied in the time domain.

\section{CONCLUSION}

The climate in Cantabria is Atlantic, with minimum precipitation and a relatively high mean temperature in July. A period of water deficit in summer is characteristic of the Mediterranean climate, while it does not happen in northernmost Atlantic regions. Thus, tree-ring climatic response of both European beech and pedunculate oak in the Cantabrian lowlands is closer to that in the Mediterranean than to the ones in other Atlantic and Central European regions. Rain deficit in July limits the radial growth of European beech and pedunculate oak. The growth of beech is influenced by the weather conditions during summer of the previous year, but oak shows a response conditioned by climate in the current year alone.

Dendroecological reconstruction of the past disturbance regime roughly coincides with the documentary sources on forest history. Two types of disturbances were identified based on the changes in radial growth patterns. The disturbances due to canopy trees removal produced an increase in the frequency of growth releases, which coincided with a decrease in the frequency of suppressions. However, the disturbance due to fungus disease produced an initial increase in the frequency of releases, followed by an increase in the frequency of growth suppressions in the host species.

The control chronologies could contain certain variations unrelated to the climate, therefore it does not exist an exact correspondence between the sequence of disturbances and the deviations from climatic signal. Furthermore, on the basis of exactly dated disturbances it becomes evident a lag in up to 6 years between the occurrence of a disturbance and the rise of a growth release. Thus the effects of disturbances in the deviation chronology are not necessarily synchronized with the sequence of growth releases. In spite of these limitations, the results obtained revealed that the impact of disturbances on the rings of mature trees differs according to the species and their shade tolerance.

Beech is a shade-tolerant species with a clear response to sharp decreases in forest density, showing strong releases even in mature trees. Therefore, in order to identify disturbances from a tolerant species it would be valid to consider a minimum threshold in the increase in radial growth throughout the life of a tree, as it is usually used [27, 31]. However, oak is intolerant to shade, and its response to disturbances becomes increasingly conservative with age and canopy dominance. The minimum threshold in radial growth increment considered to identify disturbances from intolerant species should decrease as age increases. This would avoid biases in the reconstruction of disturbance history from this species.

Also the influence of disturbances on climatic response differs according to tree species. Disturbances intensify the effects of limiting climatic variables on beech radial growth, while climatic response of mature oaks is uniform and independent of disturbances occurrence. In order to better understand this issue, the temporal variation of climatic response in relation to the past 
disturbance regime should be studied in a more exhaustive manner. The application of the Kalman filter on individual trees or groups of trees affected by known disturbances seems be the best method of studying the effects of disturbances over climatic response.

Acknowledgements: The author thanks Carlos LeQuesne for his helpful advice on dendrochronological methodology, and Luis Cabo for English language assistance. The comments and suggestions of two anonymous reviewers greatly improved the quality of the paper. The Junta Vecinal de Caviedes gave the permission for coring the trees in their forest. Jesús García, José María Para, and Elías González provided invaluable information about the past disturbance events in the Caviedes forest.

\section{REFERENCES}

[1] Abrams M.D., Copenheaver C.A., Temporal variation in species recruitment and dendroecology of an old-growth white oak forest in the Virginia Piedmont, USA, For. Ecol. Manage. 124 (1999) 275-284.

[2] Abrams M.D., Orwig D.A., DeMeo T.E., Dendroecological analysis of successional dynamics for a presettlement-origin white-pine-mixed-oak forest in the southern Appalachians, USA, J. Ecol. 83 (1995) 123-133.

[3] Abrams M.D., Ruffner C.M., DeMeo T.E., Dendroecology and species co-existence in an old-growth Quercus-Acer-Tilia talus slope forest in the central Appalachians, USA, For. Ecol. Manage. 106 (1998) 9-18.

[4] Bednarz Z., Ptak J., The influence of temperature and precipitation on ring widths of oak (Quercus robur L.) in the Niepolomice forest near Cracow, southern Poland, Tree-Ring Bull. 50 (1990) 1-10.

[5] Biondi F., Climatic signals in tree rings of Fagus sylvati$c a$ L. from the central Apennines, Italy, Acta Oecol. 14 (1993) $57-71$.

[6] Blasing T.J., Solomon A.M., Duvick D.N., Response functions revisited, Tree-Ring Bull. 44 (1984) 1-15.

[7] Brakel J.A. van den, Visser H., The influence of environmental conditions on tree-ring series of Norway spruce for different canopy and vitality classes, For. Sci. 42 (1996) 206219.

[8] Cherubini P., Piussi P., Schweingruber F.H., Spatiotemporal growth dynamics and disturbances in a subalpine spruce forest in the Alps: a dendroecological reconstruction, Can. J. For. Res. 26 (1996) 991-1001.

[9] Cook E.R., A conceptual linear aggregate model for tree rings, in: Cook E.R., Kairiukstis L.A. (Eds.), Methods of Dendrochronology: Applications in the Environmental Sciences, Kluwer Academic Publishers, Dordrecht, 1990, pp. 98-104.
[10] Cook E.R., Peters K., The smoothing spline: a new approach to standardizing forest interior tree-ring width series for dendroclimatic studies, Tree-Ring Bull. 41 (1981) 45-53.

[11] Cook E.R., Johnson A.H., Blasing T.J., Forest decline: modeling the effect of climate in tree rings, Tree Physiol. 3 (1987) 27-40.

[12] DeBona C., Memoria sobre la Explotación de los Robles por la Marina en la Provincia de Santander, Imprenta de la Gaceta de los Caminos de Hierro, Madrid, 1881.

[13] Eckstein D., Frisse E., The influence of temperature and precipitation on vessel area and ring width of oak and beech, in: Hughes M.K., Kelly P.M., Pilcher J.R., LaMarche Jr., V.C. (Eds.), Climate from Tree Rings, Cambridge University Press, Cambridge, 1982, pp. 12-13.

[14] Fritts H.C., Tree Rings and Climate, Academic Press, London, 1976.

[15] Fritts H.C., Swetnam T.W., Dendroecology: a tool for evaluating variations in past and present forest environments, Adv. Ecol. Res. 19 (1989) 111-188.

[16] Glitzenstein J.S., Harcombe P.A., Streng D.R., Disturbance, succession, and maintenance of species diversity in an east Texas forest, Ecol. Monogr. 56 (1986) 243-258.

[17] Gray B.M., Pilcher J.R., Testing the significance of summary response functions, Tree-Ring Bull. 43 (1983) 31-38.

[18] Gray B.M., Wigley T.M.L., Pilcher J.R., Statistical significance and reproducibility of tree-ring response functions, Tree-Ring Bull. 41 (1981) 21-35.

[19] Guiot J., Methods of calibration, in: Cook E.R., Kairiukstis L.A. (Eds.), Methods of Dendrochronology: Applications in the Environmental Sciences, Kluwer Academic Publishers, Dordrecht, 1990, pp. 165-178.

[20] Gutiérrez E., Dendroecological study of Fagus sylvati$c a$ L. in the Montseny mountains (Spain), Acta Oecol., Oecol. Plant. 9 (1988) 301-309.

[21] Holmes R.L., Computer-assisted quality control in treering dating and measurement, Tree-Ring Bull. 43 (1983) 6978.

[22] Hughes M.K., Gray B., Pilcher J., Baillie M., Leggett P., Climatic signals in British Isles tree-ring chronologies, Nature 272 (1978) 605-606.

[23] Ishikawa Y., Krestov P.V., Namikawa K., Disturbance history and tree establishment in old-growth Pinus koraiensishardwood forests in the Russian Far East, J. Veg. Sci. 10 (1999) 439-448.

[24] Kitzberger T., Veblen T.T., Villalba R., Tectonic influences on tree growth in Northern Patagonia, Argentina: the roles of substrate stability and climatic variation, Can. J. For. Res. 25 (1995) 1684-1696.

[25] Kobayashi O., Funada R., Yasue K., Ohtani J., Evaluation of the effects of climatic and nonclimatic factors on the radial growth of Yezo spruce (Picea jezoensis Carr.) by dendrochronological methods, Ann. Sci. For. 55 (1998) 277286.

[26] Lebourgeois F., Climatic signals in earlywood, latewood and total ring width of Corsican pine from western France, Ann. For. Sci. 57 (2000) 155-164. 
[27] Lorimer C.G., Frelich L.E., A methodology for estimating canopy disturbance frequency and intensity in dense temperate forests, Can. J. For. Res. 19 (1989) 651-663.

[28] Lusk C., Ogden J., Age structure and dynamics of a podocarp-broadleaf forest in Tongariro National Park, New Zealand, J. Ecol. 80 (1992) 379-393.

[29] Makowka I., Riemer T., Stickan W., Worbes M., Dendroclimatological studies on beech-trees (Fagus sylvatica L.) and the changing influence of climate on radial growth, in: Bartholin T.S., Berglund E., Eckstein D., Schweingruber F.H. (Eds.), Tree Rings and Environment, Proceedings of the International Dendrochronological Symposium, Ystad, Sweden, 3-9 September 1990, Lund University, Department of Quaternary Geology, Lund, 1992, pp. 217-221.

[30] McClenahen J.R., Dochinger L.S., Tree ring response of white oak to climate and air pollution near the Ohio River Valley, J. Environ. Qual. 14 (1985) 274-280.

[31] Nowacki G.J., Abrams M.D., Radial-growth averaging criteria for reconstructing disturbance histories from presettlement-origin oaks, Ecol. Monogr. 67 (1997) 225-249.

[32] Orwig D.A., Abrams M.D., Variation in radial growth responses to drought among species, site, and canopy strata, Trees 11 (1997) 474-484.

[33] Peters R., Poulson T.L., Stem growth and canopy dynamics in a world-wide range of Fagus forests, J. Veg. Sci. 5 (1994) 421-432.

[34] Pilcher J.R., Gray B., The relationships between oak tree growth and climate in Britain, J. Ecol. 70 (1982) 297-304.

[35] Piutti E., Cescatti A., A quantitative analysis of the interactions between climatic response and intraspecific competition in European beech, Can. J. For. Res. 27 (1997) 277284.

[36] Rozas V., Estructura, dinámica y tendencias sucesionales en un bosque de roble y haya de la cornisa cantábrica, Ph.D. dissertation, Universidad de Oviedo, 1999.
[37] Ruffner C.M., Abrams M.D., Relating land-use history and climate to the dendroecology of a 326-year-old Quercus prinus talus slope forest, Can. J. For. Res. 28 (1998) 347-358.

[38] Santini A., Bottacci A., Gellini R., Preliminary dendroecological survey on pedunculate oak (Quercus robur L.) stands in Tuscany (Italy), Ann. Sci. For. 51 (1994) 1-10.

[39] Splechtna B.E., Dobry J., Klinka K., Tree-ring characteristics of subalpine fir (Abies lasiocarpa (Hook.) Nutt.) in relation to elevation and climatic fluctuations, Ann. For. Sci. 57 (2000) 89-100.

[40] Stokes M.A., Smiley T.L., An Introduction to TreeRing Dating, University of Chicago Press, Chicago, 1968.

[41] Swetnam T.W., Lynch A.M., Multicentury, regionalscale patterns of western spruce budworm outbreaks, Ecol. Monogr. 63 (1993) 399-424.

[42] Tessier L., Nola P., Serre-Bachet F., Deciduous Quercus in the Mediterranean region: tree-ring/climate relationships, New Phytol. 126 (1994) 355-367.

[43] Van Deusen P.C., Evaluating time-dependent tree ring and climate relationships, J. Environ. Qual. 19 (1990) 481488.

[44] Veblen T.T., Kitzberger T., Lara A., Disturbance and forest dynamics along a transect from Andean rain forest to Patagonian shrubland, J. Veg. Sci. 3 (1992) 507-520.

[45] Visser H., Analysis of tree ring data using the Kalman filter technique, IAWA Bull. 7 (1986) 29-37.

[46] Visser H., Molenaar J., Time-dependent responses of trees to weather variations: an application of the Kalman filter, in: Jacoby G.C., Hornbeck J.W. (Eds.), Proceedings of the International Symposium on Ecological Aspects of Tree-Ring Analysis, U.S. Department of Energy, Washington D.C., 1987, pp. 579-590.

[47] Visser H., Molenaar J., Kalman filter analysis in dendroclimatology, Biometrics 44 (1988) 929-940.

To access this journal online: www.edpsciences.org 